Article

\title{
Highly Efficient Aggregation-Induced Room-Temperature Phosphorescence with Extremely Large Stokes Shift Emitted from Trinuclear Gold(I) Complex Crystals
}

\author{
Osamu Tsutsumi *(D, Masakazu Tamaru, Hitoya Nakasato, Shingo Shimai, Supattra Panthai $\mathbb{D}^{\text {, }}$ \\ Yuki Kuroda ${ }^{\mathbb{D}}$, Kenta Yamaguchi, Kaori Fujisawa and Kyohei Hisano ${ }^{D}$ \\ Department of Applied Chemistry, Ritsumeikan University, 1-1-1 Nojihigashi, Kusatsu 525-8577, Japan; \\ konbudashi22@gmail.com (M.T.); 27111000455nz@gmail.com (H.N.); shingo1220535@gmail.com (S.S.); \\ gr0344hv@ed.ritsumei.ac.jp (S.P.); sc0050ir@ed.ritsumei.ac.jp (Y.K.); sc0075vi@ed.ritsumei.ac.jp (K.Y.); \\ kfujisawa@kyulux.com (K.F.); hisano@fc.ritsumei.ac.jp (K.H.) \\ * Correspondence: tsutsumi@sk.ritsumei.ac.jp; Tel./Fax: +81-77-561-5966 \\ Academic Editor: F. Christopher Pigge \\ Received: 25 November 2019; Accepted: 12 December 2019; Published: 16 December 2019

\begin{abstract}
Highly efficient ( $\approx 75 \%$ quantum yield), aggregation-induced phosphorescence is reported. The phosphorescence is emitted at room temperature and in the presence of air from crystals of trinuclear $\mathrm{Au}(\mathrm{I})$ complexes, accompanied by an extremely large Stokes shift of $2.2 \times 10^{4} \mathrm{~cm}^{-1}(450 \mathrm{~nm})$. The mechanism of the aggregation-induced room-temperature phosphorescence from the Au complex crystals was investigated in terms of the crystal packing structure and the primary structure of the molecules. It was found that two kinds of intermolecular interactions occurred in the crystals, and that these multiple dual-mode intermolecular interactions in the crystals play a crucial role in the in-air room-temperature phosphorescence of the trinuclear $\mathrm{Au}(\mathrm{I})$ complexes.
\end{abstract}

Keywords: Au complex; aggregation-induced emission; phosphorescence; Stokes shift

\section{Introduction}

Aggregation-induced emission (AIE) is a fascinating phenomenon wherein molecules display intense luminescence by aggregation [1-3]. Organic molecules can exhibit efficient luminescence in dilute solutions, but their luminescence efficiency is decreased by aggregation in condensed phases by aggregation-caused quenching (ACQ), a well-known phenomenon which is very common among organic luminescent molecules [3-6]. However, the development of practical applications using luminescent molecules is hindered by the ACQ of conventional luminogens; and attaining intensive photoluminescence in condensed phases or aggregates is a vital parameter for improving their usefulness. To address the recent demand for efficient luminescence materials in molecular aggregates, AIE-active luminogens (AIEgens) have been developed, and have attracted prime interest as practical luminescent materials for biological imaging, chemical sensing, optoelectronic systems, and related applications [7-12]. A general working mechanism of the AIE involves restriction of intramolecular motions that lead to non-radiative deactivation of excited states, such as vibration and rotation, due to aggregation [1-3]. Great effort has been devoted to further restricting intramolecular motions using the intermolecular interactions of AIEgens.

Molecules containing $\mathrm{Au}(\mathrm{I})$ ions are examples of AIEgens that exhibit strong photoluminescence in condensed phases [13-17]. The aurophilic interaction between Au atoms in Au containing complexes is an important property which induces luminescence in their aggregates $[13,14]$. As luminescence 
results from the $\mathrm{Au}-\mathrm{Au}$ interaction, $\mathrm{Au}$ complexes exhibit unique luminescence in their condensed phase, and their luminescence properties, such as intensity or color, depend on the Au-Au distance, which can be tuned by modifying the structure of their aggregates [18-31]. Thus far, modifications to structures of molecular aggregates in the solids by external stimuli have been reported for modifying the photoluminescence properties of Au complexes [8-11]. For instance, in Au complexes exhibiting polymorphism, the thermal phase transition causes a drastic change in the luminescence color and intensity [26-31].

In this study, we designed trinuclear Au complexes represented by DT $n(n=6-8)$ to induce multiple Au-Au interactions (Scheme 1) [32-34], and investigated their luminescence behaviors in solids. We hypothesized that multiple interactions could enhance AIE activity, and that very efficient AIE could be obtained from trinuclear Au complex solid materials [19-21]. The stabilization energy of the Au-Au interaction is as large as that of the hydrogen bond [13-16], and for this reason it is often utilized for the formation of supramolecular assemblies [18-21]. We also anticipated that multiple $\mathrm{Au}-\mathrm{Au}$ intermolecular interactions would improve the restriction of the internal motion and would further enhance the AIE effects in condensed phases of the complexes. Previously, the luminescence behavior of DT6 (Scheme 1) in a poly(methyl methacrylate) (PMMA) dispersion was reported; the complex showed efficient phosphorescence in PMMA films [34]. In this study, the mechanism of the efficient phosphorescence of the trinuclear complexes DT $n$ is discussed in relation to the structures of the molecular aggregates. Therefore, the luminescence behaviors of the complexes were observed in crystal, in where the molecular aggregated structure is well defined, to understand the relationship between aggregated structure and photophysical properties. Here, we report that the complex crystals emitted highly efficient room-temperature phosphorescence (RTP) in the presence of air, accompanied by an extremely large Stokes shift. The mechanism of the in-air RTP from the crystals of complexes is discussed in terms of the structures of the molecular aggregates in the crystals.

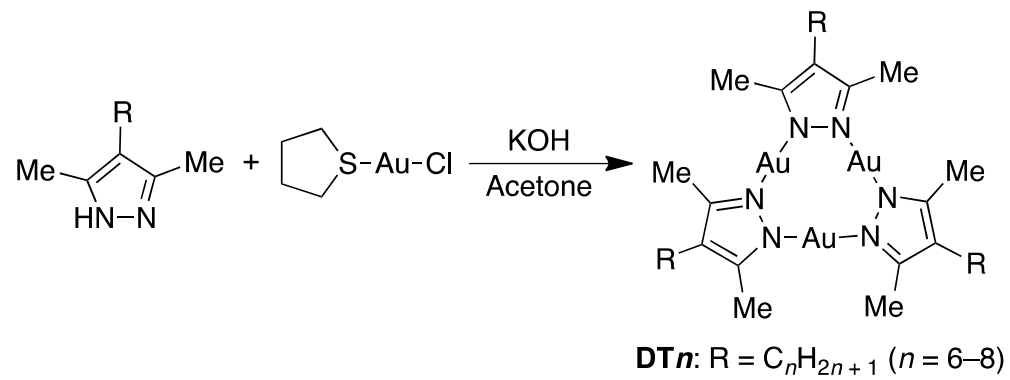

Scheme 1. Synthesis and molecular structure of the trinuclear Au(I) complexes DT $n$.

\section{Results and Discussion}

\subsection{Synthesis and Characterization of Complexes}

The molecular structure and synthesis of DTnare shown in Scheme 1. Our molecular design strategy centered around the use of a simple ligand without bulky substituents around the Au atoms to improve the $\mathrm{Au}-\mathrm{Au}$ intermolecular interaction, which is typically blocked by the steric hindrance of bulky ligands. Therefore, a simple pyrazole derivative with a long n-alkyl side chain at the 4-position was designed as the ligand for the trinuclear Au complexes. The pyrazole ligands were synthesized from commercially available 2,4-pentanedione in two steps. The trinuclear Au complexes DTnwere then prepared by complexation of (tht) $\mathrm{AuCl}$ (tht: tetrahydrothiophene) and the corresponding pyrazole ligands [32-34]. All the synthesized complexes were purified by silica gel column chromatography and recrystallisation. The complexes were fully characterized, and the analytical data confirmed that the desired complexes were obtained in high purity. The related analytical data are provided in the experimental section. Details of the preparation of the pyrazole ligands are provided in the Electronic Supplementary Information (ESI) and ${ }^{1} \mathrm{H}$ and ${ }^{13} \mathrm{C}-\mathrm{NMR}$ spectra of the final compounds are shown in Figures S1-S3. 


\subsection{Photoluminescence Behavior of the Complexes}

The recrystallized complexes were placed between a pair of quartz plates and irradiated with UV light at $254 \mathrm{~nm}$ at ambient temperature in the presence of air. Bright red photoluminescence could be observed from all complexes using the naked eye (Figure 1a). The emission and excitation spectra of the Au complex crystals at ambient temperature are shown in Figure 1b, and the quantitative photophysical parameters for the room-temperature photoluminescence of the crystals are summarized in Table 1 . The crystals of all the complexes exhibited broad unstructured luminescence at around $730 \mathrm{~nm}$ with significantly high quantum yields $(\Phi)$. The highest $\Phi$ was obtained for the DT6 crystal; $\Phi$ was 75\% for DT6, while it was $\sim 60 \%$ for the other complexes. In contrast, we could not observe such intense luminescence in dilute solutions of any of the complexes. Figure 1c shows the luminescence spectra of DT6 in hexane solutions as a representative example. A $10^{-5} \mathrm{~mol} \mathrm{~L}^{-1}$ solution of DT6 exhibited no luminescence, and only very weak luminescence was observed at the same wavelength as in the crystal in a concentrated solution $\left(10^{-3}\right.$ mol L ${ }^{-1}$ ). Hexane is actually a poor solvent for these complexes, and it can be assumed that aggregates of the complexes are formed in concentrated hexane solutions. These results indicate that the trinuclear Au complexes we prepared cannot emit luminescence in dilute solution, wherein only isolated molecules exist, which suggests that the DTncomplexes are AIE active and that the luminescence of the complexes is induced by the formation of aggregates. The AIE activity was further confirmed through the observation of luminescence behavior in the mixed solvent system for DT6 (Figure S7d). In pure $\mathrm{CH}_{2} \mathrm{Cl}_{2}$, which is a good solvent for DT6, the complex showed no luminescence; however, the addition of methanol, which is a poor solvent, to the solution with the volume fraction of $>80 \%$ to induce the aggregation of molecules, significantly enhanced the emission (Figure S7e).

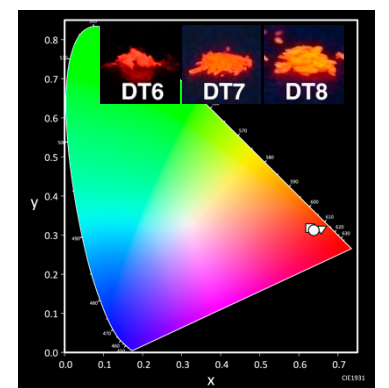

(a)

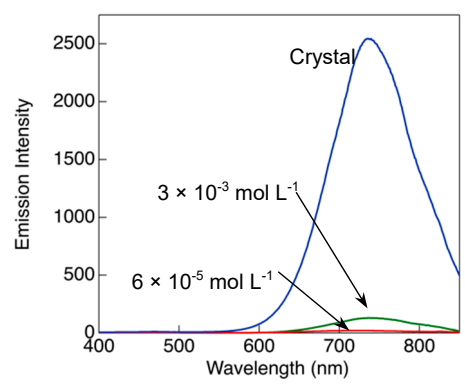

(c)

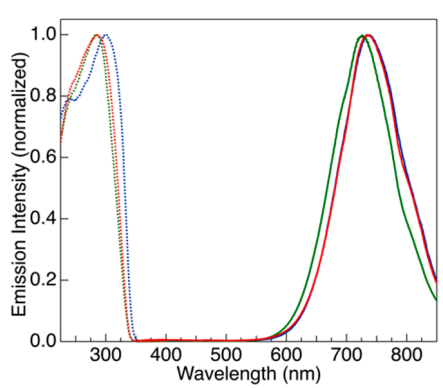

(b)

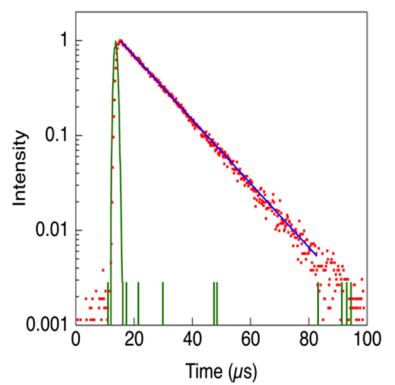

(d)

Figure 1. (a) Photograph of crystals taken under UV irradiation at $254 \mathrm{~nm}$ using a handheld lamp, and CIE (Commission Internationale de l'Éclairage) chromaticity diagram of the photoluminescence of the crystals: •, DT6; $\mathbf{v}$, DT7; $\mathbf{\square}$, DT8. (b) Photoluminescence (solid line) and excitation spectra (dotted line) of the crystals of DT $n$ at room temperature in air (red: DT6, green: DT7, blue: DT8). The excitation wavelength $\left(\lambda_{\text {ex }}\right)$ was $280 \mathrm{~nm}$ for the luminescence spectra, and the luminescence was monitored at their $\lambda_{\max }{ }^{\text {lum }}$ for the excitation spectra (Table 1). (c) Photoluminescence spectra of DT6 in crystalline form and in hexane solutions $\left(\lambda_{\mathrm{ex}}=280 \mathrm{~nm}\right)$. Concentrations of the hexane solutions are indicated in the Figure. (d) Decay profile of the luminescence of the DT6 crystal at $733 \mathrm{~nm}$ at ambient temperature $\left(\lambda_{\mathrm{ex}}=330 \mathrm{~nm}\right.$; pulse width $\left.=600 \mathrm{ps}\right)$ : red, observed luminescence decay; blue, fitting curve; green, instrument response function. 
Table 1. Photophysical parameters of the crystalline complexes observed at room temperature in the presence of air.

\begin{tabular}{cccccc}
\hline Sample & $\lambda_{\max }{ }^{\operatorname{lum}}[\mathrm{nm}]^{\text {a) }}$ & $\boldsymbol{\Phi}^{\text {a,b) }}$ & $\tau[\boldsymbol{\mu s}]$ & $\boldsymbol{k}_{\mathrm{r}}\left[\mathbf{s}^{-\mathbf{1}}\right]^{\mathrm{c})}$ & $\boldsymbol{k}_{\mathrm{nr}}\left[\mathbf{s}^{-\mathbf{1}}\right]^{\mathrm{c})}$ \\
\hline DT6 & 733 & 0.748 & 13 & $5.8 \times 10^{4}$ & $1.9 \times 10^{4}$ \\
DT7 & 726 & 0.609 & 13 & $4.7 \times 10^{4}$ & $3.0 \times 10^{4}$ \\
DT8 & 733 & 0.625 & 12 & $5.2 \times 10^{4}$ & $3.1 \times 10^{4}$
\end{tabular}

a) Excitation wavelength was $280 \mathrm{~nm}$ for steady-state measurements. ${ }^{\text {b) }}$ The luminescence intensity was integrated from $350 \mathrm{~nm}$ to $875 \mathrm{~nm}$ for estimation of $\Phi$ (Figure S8). The measurements were performed in triplicate to check reproducibility, and the averaged value is indicated here. ${ }^{c} k_{\mathrm{r}}$, the rate constant for radiative transition was estimated by $\Phi / \tau$, and $k_{\mathrm{nr}}$, the rate constant for non-radiative deactivation was estimated by $(1-\Phi) / \tau$.

Notably, the complexes displayed extremely large Stokes shifts. The absorption maxima of the complexes in dilute solutions were around $250 \mathrm{~nm}$ (Figure S6), and the absorption maxima of the crystals, estimated from the excitation spectra (Figure 1b) were located at $280 \mathrm{~nm}$. Therefore, the crystals displayed a Stokes shift of at least $2.2 \times 10^{4} \mathrm{~cm}^{-1}(450 \mathrm{~nm})$ in all complexes. This feature is highly favorable for their application as imaging and sensing materials [1-3].

To obtain more information about the photoluminescence properties of the complexes, we measured the luminescence lifetime $(\tau)$ of their crystals at the wavelength of their luminescence maxima $\left(\lambda_{\max }{ }^{\text {lum }}\right)$. The luminescence decay profile for the DT6 crystal is shown in Figure $1 \mathrm{~d}$ as a representative example. The crystals of all the complexes exhibited a single-exponential decay profile at room temperature (Figure $1 \mathrm{~d}$ and Figure S9). The $\tau$ values determined from the decay profile were in the microsecond range for all the complexes, indicating that the observed luminescence of the crystals at room temperature was phosphorescence. Although the luminescence was phosphorescence, the crystals of the prepared complexes exhibited very high $\Phi$ values at room temperature in the presence of air $(\Phi=61 \%-75 \%)$. It is well-known that the triplet excited state is easily quenched by the molecular oxygen in air. In addition, the rate constants for phosphorescence emission $\left(k_{\mathrm{r}}\right)$ are much smaller than those of non-radiative deactivation processes $\left(k_{\mathrm{nr}}\right)$ at ambient temperature, as the $\mathrm{T}_{1}-\mathrm{S}_{0}$ radiative transition is a spin-forbidden process. Therefore, although it has been reported that some specific organic and organometallic materials exhibit RTP recently [1-3], phosphorescence is typically observed only at low temperatures in the absence of oxygen molecules. Considering such sensitivity, it is noteworthy that the complexes reported here exhibited high $\Phi$ values under room-temperature conditions in the presence of air.

\subsection{Relationship between the Room-Temperature Phosphorescence Properties and Aggregated Structure}

To understand the underlying reason for the efficient in-air RTP of the DT $n$ crystals, we analyzed their crystal structures. Single crystals of all the complexes were obtained by slow evaporation from a mixed solvent system of dichloromethane and acetone, and analyses of their single-crystal X-ray structures were performed. Their crystal packing structures are shown in Figure 2, Figures S4 and S5, in which two neighboring molecules are extracted and shown to discuss their intermolecular interactions in the crystals. The related key crystallographic data is listed in Table S1. Select interatomic distances between neighboring complexes are summarized in Table 2 to analyze the structure-property relationships of the complexes. The X-ray structure analysis of DT $n$ indicated that the intermolecular $\mathrm{Au}-\mathrm{Au}$ distance was $3.40 \AA$ or less. It is generally accepted that the $\mathrm{Au}-\mathrm{Au}$ distance is in the range of $2.50-3.50 \AA$, substantially shorter than the sum of the van der Waals radii (3.8 $\AA$ ) of two Au atoms, suggesting the existence of an aurophilic interaction between them [16]. Furthermore, the Au atom was located close to the pyrazole ring of the neighboring molecule; the distance between the $\mathrm{Au}$ atom and centroid of the pyrazole ring was determined to be $3.58 \AA$ or less, and the angle between the vector normal to the pyrazole ring and that passing through the centroid of the Au atom $(\theta)$ was $2.4^{\circ}-15^{\circ}$. Au complexes form aggregates due to the interactions between the Au atoms and aromatic $\pi$-electron systems ( $\mathrm{Au}-\pi$ interaction) when the distance between them is less than $4.0 \AA$, with the $\theta$ angle being equal to or less than $20^{\circ}$ [35]. Therefore, the geometric parameters obtained 
from the single-crystal structural analysis of DT $n$ indicated the presence of an intermolecular Au- $\pi$ interaction between neighboring molecules. The analysis further indicated that all the complexes formed dimers in the crystal via both non-covalent $\mathrm{Au}-\mathrm{Au}$ and $\mathrm{Au}-\pi$ intermolecular interactions (Figure 2c, Figures S4 and S5).

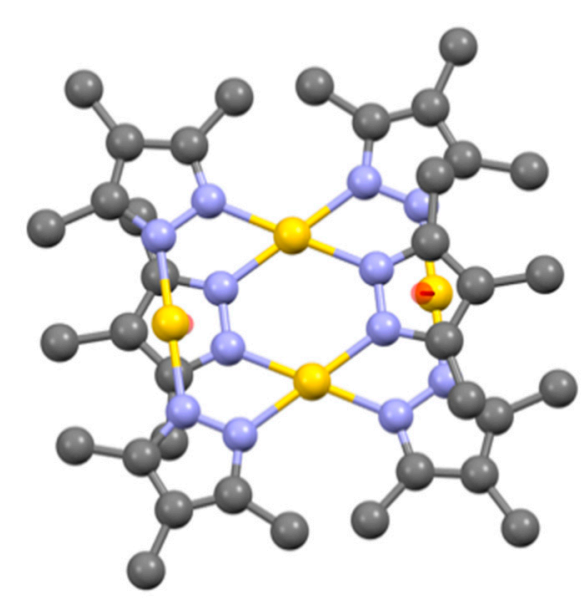

(a)

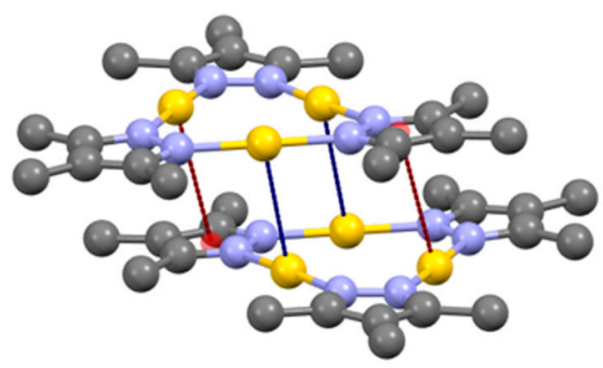

(c)

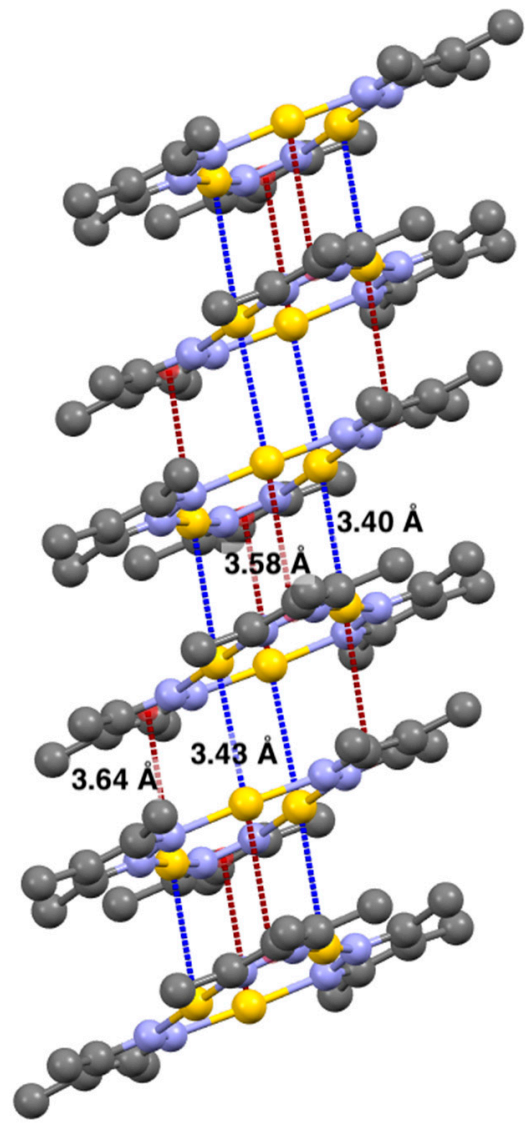

(b)

Figure 2. Crystal structure of DT6 at room temperature. (a,c) Structure of the dimer: (a) top view; (c) side view. (b) Structure of the column-like supramolecular polymer; three dimers are extracted from the polymer. For clarity, $\mathrm{H}$ atoms and alkyl side chains are omitted. Atom color legend: grey, C; purple, $\mathrm{N}$; yellow, $\mathrm{Au}$; red, the centroid of pyrazole ring. Intermolecular $\mathrm{Au}-\mathrm{Au}$ and $\mathrm{Au}-\pi$ interactions are indicated using blue and red lines, respectively.

Table 2. Selected distances and angles between the closest neighboring molecules in room-temperature crystals of DTn.

\begin{tabular}{cccc}
\hline Sample & $\mathbf{A u}-\mathbf{A u}$ Distance $[\AA ̊ \AA]$ & $\mathbf{A u}-\boldsymbol{\pi}$ Distance $[\AA ⿻)$ & $\boldsymbol{\theta}[\mathbf{d e g}]^{\text {a) }}$ \\
\hline DT6 & 3.40 & 3.58 & 15 \\
DT7 & 3.29 & 3.38 & 2.4 \\
DT8 & 3.25 & 3.39 & 7.0
\end{tabular}

a) The angle, $\theta$, was defined as the angle between the vector normal to the pyrazole ring and that passing through the centroid to the $\mathrm{Au}$ atom.

In order to clarify the luminescence mechanism in the crystal, the molecular orbitals, transition energies, and oscillator strengths $(f)$ of the complexes were calculated using time-dependent density functional theory (TD-DFT) computations. The calculations were performed for the dimer model formed in the DT6 crystal, as a representative example, using the initial conformation obtained from X-ray crystallography (Figure 2). The DFT calculations suggested that there are three allowed 
electron transitions are in the UV region; viz., HOMO $\rightarrow$ LUMO at $267.23 \mathrm{~nm}(f=0.0002), \mathrm{HOMO}-2$ $\rightarrow$ LUMO at $262.04 \mathrm{~nm}(f=0.0033)$, and $\mathrm{HOMO} \rightarrow \mathrm{LUMO}+2$ at $255.46 \mathrm{~nm}(f=0.0292)$ (see ESI). The calculations' results were almost consistent with the excitation spectra of the complexes in the crystal (Figure 1b). As shown in Figure 3, the HOMO and HOMO-2 are delocalized mainly over the pyrazole ring, and the LUMO and LUMO+2 are localized mainly on a non-covalent aurophilic bonding between $\mathrm{Au}-\mathrm{Au}$ atoms. Therefore, the results indicate that those electronic transitions in the excitation spectra can be assigned as a ligand-to-metal-metal charge transfer (LMMCT) transition. The broad photoluminescence band without vibronic structures observed at $\sim 730$ is consistent with the previously reported luminescence band for crystal of similar Au complexes [13,14], and it has been proposed that the luminescence is originated from metal-centered excimeric states based on the $\mathrm{Au}-\mathrm{Au}$ interaction [14]. The computational results also support that the luminescence in the DT $n$ crystals was emitted from the metal-centered excimeric states.

Top view
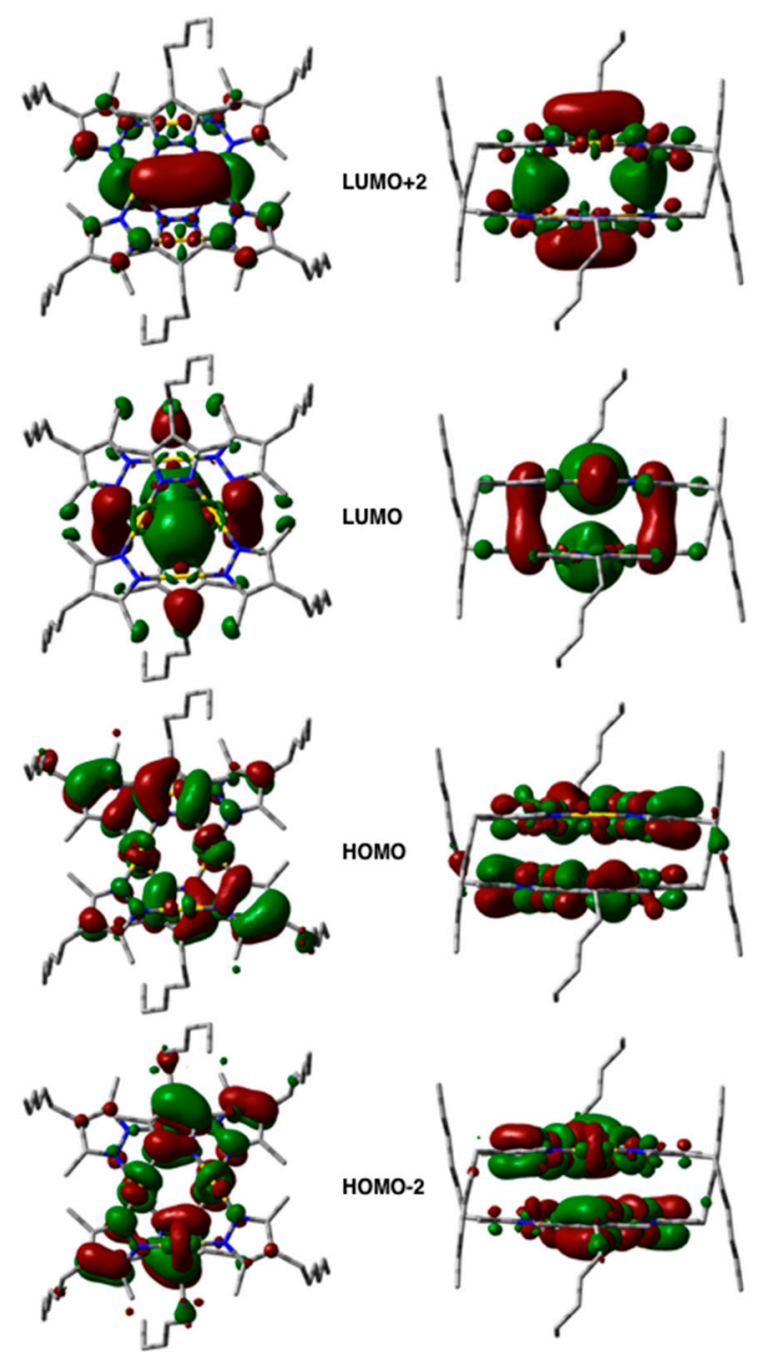

Side view
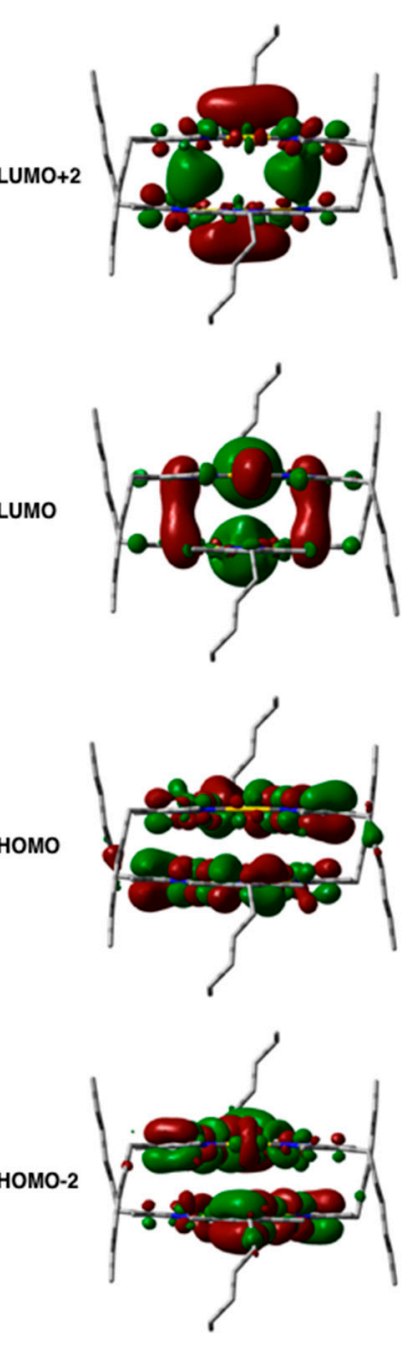

Figure 3. Molecular orbitals. of the DT6 dimer obtained using DFT calculations employing B3LYP hybrid functionals with SDD (for Au atoms) and 6-311+G(d,p) (for the other atoms).

As shown in Figure 2c, Figure S4 and S5, in all the complexes, both $\mathrm{Au}-\mathrm{Au}$ and $\mathrm{Au}-\pi$ interactions exist at two sites in each dimer. Additionally, both interactions are extended in DT6, as a result of which, the DT6 dimers stack to form a column-like supramolecular polymer (Figure 2b). In contrast, these interactions are not extended in DT7 and DT8 crystals, and their dimers exist independently 
(Figure S4 and S5). We concluded that these multiple dual-mode intermolecular interactions forming the dimer and polymer were the cause of the highly efficient, in-air RTP observed in this system, which is likely enhanced due to the following three key effects: (i) The crystallinity of the complexes we prepared can prevent penetration of molecular oxygen from the air into the densely packed crystal lattice, as previously proposed by Tang et al. [36-38]. (ii) In the present system, the multiple intermolecular interactions can further restrict the internal motions in the crystal; therefore, $k_{\mathrm{nr}}$ is decreased more effectively, and the $\Phi$ of phosphorescence is increased, which is in line with the general working mechanism of AIE [1-3]. (iii) Each molecule in the developed system has three heavy Au atoms, which induce both internal and external heavy atom effects simultaneously. Consequently, both $k_{\mathrm{r}}$ and the rate constant for the spin-forbidden singlet-triplet intersystem crossing are effectively improved by the internal/external heavy atom effects. A combination of these effects likely brought about the very high $\Phi$ value in the in-air RTP. The multiple dual-mode intermolecular interactions observed in the crystals can increase the density of the molecular packing and can amplify all the aforementioned effects, resulting in highly efficient in-air RTP. Especially in DT6, the presence of extended, multiple dual-mode interactions would be expected to afford the strongest amplification, which was the case, and DT6 showed the highest $\Phi$ value for the in-air RTP among the complexes prepared.

\section{Materials and Methods}

\subsection{Preparation of Materials}

The complete synthetic route for the preparation of the trinuclear $\mathrm{Au}(\mathrm{I})$ complexes (DTn) is shown in Scheme S1. The complexes DTn were synthesized from the corresponding 4-alkyl-3,5-dimethylpyrazole ligand and (tht) $\mathrm{AuCl}$, according to the procedure reported, with some modifications to the purification processes [32-34]. Unless otherwise noted, all solvents and reagents were purchased from commercial suppliers and were used without further purification. ${ }^{1} \mathrm{H}$ NMR spectra were recorded using a ECS-400 spectrometer (JEOL, Tokyo, Japan) at $400 \mathrm{MHz}$ using the residual proton in the NMR solvent as an internal reference. The complexes were fully characterized by high-resolution mass spectroscopy (HRMS), infrared spectroscopy (IR), and elemental analysis. Electrospray ionization mass spectra (ESI-MS) were measured using a JMS-T1000LC (JEOL, Tokyo, Japan). IR spectra were recorded using a FT/IR-4100 spectrometer (JASCO, Tokyo, Japan) as a KBr pellet. The melting points of the final products were determined as the peak onset in differential scanning calorimetry (DSC) with heating and cooling rates of $1.0^{\circ} \mathrm{C} \mathrm{min}-1$.

DT6. 4-Hexyl-3,5-dimethylpyrazole $(0.51 \mathrm{~g}, 2.8 \mathrm{mmol})$ and (tht) $\mathrm{AuCl}(1.0 \mathrm{~g}, 3.2 \mathrm{mmol})$ were dissolved in $30 \mathrm{~mL}$ of acetone. A $1.0 \mathrm{~mol} \mathrm{~L}^{-1}$ methanol solution $(3.0 \mathrm{~mL})$ of potassium hydroxide was added to the reaction mixture slowly ( 2 drops per second) with stirring. The solution was stirred for $2 \mathrm{~h}$ at room temperature, after which the white precipitate formed was collected by filtration. The crude product was purified on a silica gel column (eluent: $\mathrm{CH}_{2} \mathrm{Cl}_{2}$ ), and then recrystallized from a mixture of dichloromethane and acetone to give $0.69 \mathrm{~g}(0.61 \mathrm{mmol})$ of colorless needles (DT6) in $65 \%$ yield. mp $134{ }^{\circ} \mathrm{C} .{ }^{1} \mathrm{H}$ NMR $\left(400 \mathrm{MHz}, \mathrm{CDCl}_{3}, \delta\right): 2.31(\mathrm{t}, J=7.2 \mathrm{~Hz} ; 6 \mathrm{H}$; $\left.\mathrm{CH}_{2}\left(\mathrm{CH}_{2}\right)_{4} \mathrm{CH}_{3}\right), 2.15\left(\mathrm{~s}, 18 \mathrm{H}\right.$; pyrazole- $\left.\mathrm{CH}_{3}\right), 1.28-1.41\left(\mathrm{~m}, 24 \mathrm{H} ; \mathrm{CH}_{2}\left(\mathrm{CH}_{2}\right)_{4} \mathrm{CH}_{3}\right), 0.88(\mathrm{t}, J=6.8 \mathrm{~Hz} ; 9 \mathrm{H}$; $\left.\left(\mathrm{CH}_{2}\right)_{5} \mathrm{CH}_{3}\right) .{ }^{13} \mathrm{C}$ NMR (100 MHz, $\left.\mathrm{CDCl}_{3}, \delta\right): 145.71$ (3,5-C in pyrazole), 115.73 (4-C in pyrazole), 32.16 (pyrazole- $\left.\mathrm{CH}_{3}\right), 31.25\left(-\mathrm{CH}_{2}\left(\mathrm{CH}_{2}\right)_{4} \mathrm{CH}_{3}\right), 29.44\left(\mathrm{CH}_{2} \mathrm{CH}_{2}\left(\mathrm{CH}_{2}\right)_{3} \mathrm{CH}_{3}\right), 24.48\left(\left(\mathrm{CH}_{2}\right)_{2} \mathrm{CH}_{2}\left(\mathrm{CH}_{2}\right)_{2} \mathrm{CH}_{3}\right)$, $23.08\left((\mathrm{CH} 2)_{3} \mathrm{CH}_{2} \mathrm{CH}_{2} \mathrm{CH}_{3}\right), 14.50\left(\left(\mathrm{CH}_{2}\right)_{4} \mathrm{CH}_{2} \mathrm{CH}_{3}\right), 12.34\left(\left(\mathrm{CH}_{2}\right)_{5} \mathrm{CH}_{3}\right)$. FTIR $(\mathrm{KBr}): v=2956 \mathrm{~cm}^{-1}$ $(\mathrm{C}-\mathrm{H}), 2922 \mathrm{~cm}^{-1}(\mathrm{C}-\mathrm{H}), 2852 \mathrm{~cm}^{-1}(\mathrm{C}-\mathrm{H}), 1515 \mathrm{~cm}^{-1}(\mathrm{C}=\mathrm{C}), 1456 \mathrm{~cm}^{-1}(\mathrm{C}=\mathrm{C}), 1429 \mathrm{~cm}^{-1}(\mathrm{C}=\mathrm{N}), 1371$ $\mathrm{cm}^{-1}(\mathrm{C}-\mathrm{H})$. Combustion elemental analysis calculated for $\mathrm{C}_{33} \mathrm{H}_{57} \mathrm{Au}_{3} \mathrm{~N}_{6}$ : C, 35.11; H, 5.09; N, 7.45; $\mathrm{Au}, 52.35$. Found: C, 34.88; H, 4.94; N, 7.37; Ash, 48.4.

DT7 and DT8. Compounds DT7 and DT8 were obtained by substituting 4-heptyl-3,5-dimethylpyrazole and 4-octyl-3,5-dimethylpyrazole for 4-hexyl-3,5-dimethylpyrazole in the above procedure, respectively. 
DT7: $\mathrm{mp} 117{ }^{\circ} \mathrm{C} .{ }^{1} \mathrm{H} \mathrm{NMR}\left(400 \mathrm{MHz}, \mathrm{CDCl}_{3}, \delta\right): 2.31\left(\mathrm{t}, \mathrm{J}=7.5 \mathrm{~Hz} ; 6 \mathrm{H} ; \mathrm{CH}_{2}\left(\mathrm{CH}_{2}\right)_{5} \mathrm{CH}_{3}\right), 2.13$ (s, 18H; pyrazole- $\left.\mathrm{CH}_{3}\right), 1.28-1.43\left(\mathrm{~m}, 30 \mathrm{H} ; \mathrm{CH}_{2}\left(\mathrm{CH}_{2}\right)_{5} \mathrm{CH}_{3}\right), 0.88\left(\mathrm{t}, \mathrm{J}=6.8 \mathrm{~Hz} ; 9 \mathrm{H} ;\left(\mathrm{CH}_{2}\right)_{6} \mathrm{CH}_{3}\right)$. ${ }^{13} \mathrm{C}$ NMR (100 MHz, $\left.\mathrm{CDCl}_{3}, \delta\right): 145.51$ (3,5-C in pyrazole), 115.89 (4-C in pyrazole), 32.29 (pyrazole- $\left.\mathrm{CH}_{3}\right), 31.26\left(-\mathrm{CH}_{2}\left(\mathrm{CH}_{2}\right)_{5} \mathrm{CH}_{3}\right), 29.72\left(\mathrm{CH}_{2} \mathrm{CH}_{2}\left(\mathrm{CH}_{2}\right)_{4} \mathrm{CH}_{3}\right), 29.60\left(\left(\mathrm{CH}_{2}\right)_{2} \mathrm{CH}_{2}\left(\mathrm{CH}_{2}\right)_{3} \mathrm{CH}_{3}\right)$, $24.43\left(\left(\mathrm{CH}_{2}\right)_{3} \mathrm{CH}_{2}\left(\mathrm{CH}_{2}\right)_{2} \mathrm{CH}_{3}\right), 23.05\left(\left(\mathrm{CH}_{2}\right)_{4} \mathrm{CH}_{2} \mathrm{CH}_{2} \mathrm{CH}_{3}\right), 14.50\left(\left(\mathrm{CH}_{2}\right)_{5} \mathrm{CH}_{2} \mathrm{CH}_{3}\right), 12.41\left(\left(\mathrm{CH}_{2}\right)_{6} \mathrm{CH}_{3}\right)$. FTIR (KBr): $v=2955 \mathrm{~cm}^{-1}(\mathrm{C}-\mathrm{H}), 2922 \mathrm{~cm}^{-1}(\mathrm{C}-\mathrm{H}), 2852 \mathrm{~cm}^{-1}(\mathrm{C}-\mathrm{H}), 1515 \mathrm{~cm}^{-1}(\mathrm{C}=\mathrm{C}), 1465 \mathrm{~cm}^{-1}$ $(C=C), 1452 \mathrm{~cm}^{-1}(\mathrm{C}=\mathrm{C}), 1436 \mathrm{~cm}^{-1}(\mathrm{C}=\mathrm{N}), 1374 \mathrm{~cm}^{-1}(\mathrm{C}-\mathrm{H}), 1357 \mathrm{~cm}^{-1}(\mathrm{C}-\mathrm{H})$. Combustion elemental analysis calculated for $\mathrm{C}_{36} \mathrm{H}_{63} \mathrm{Au}_{3} \mathrm{~N}_{6}$ : C, 36.93; H, 5.42; N, 7.18; $\mathrm{Au}, 50.47$. Found: $\mathrm{C}, 36.60 ; \mathrm{H}, 5.38 ; \mathrm{N}$, 7.16; Ash, 36.6.

DT8: $\mathrm{mp} 114{ }^{\circ} \mathrm{C} .{ }^{1} \mathrm{H} \mathrm{NMR}\left(400 \mathrm{MHz}, \mathrm{CDCl}_{3}, \delta\right): 2.30\left(\mathrm{t}, \mathrm{J}=7.5 \mathrm{~Hz} ; 6 \mathrm{H} ; \mathrm{CH}_{2}\left(\mathrm{CH}_{2}\right)_{6} \mathrm{CH}_{3}\right), 2.11$ (s, 18H; pyrazole- $\left.\mathrm{CH}_{3}\right), 1.27-1.41\left(\mathrm{~m}, 36 \mathrm{H} ; \mathrm{CH}_{2}\left(\mathrm{CH}_{2}\right)_{6} \mathrm{CH}_{3}\right), 0.88\left(\mathrm{t}, \mathrm{J}=6.8 \mathrm{~Hz} ; 9 \mathrm{H} ;\left(\mathrm{CH}_{2}\right)_{7} \mathrm{CH}_{3}\right)$. ${ }^{13} \mathrm{C}$ NMR (100 MHz, $\left.\mathrm{CDCl}_{3}, \delta\right): 145.51$ (3,5-C in pyrazole), 115.58 (4-C in pyrazole), 32.29 (pyrazole-CH3), $31.30\left(-\mathrm{CH}_{2}\left(\mathrm{CH}_{2}\right)_{6} \mathrm{CH}_{3}\right), 29.92\left(\mathrm{CH}_{2} \mathrm{CH}_{2}\left(\mathrm{CH}_{2}\right)_{5} \mathrm{CH}_{3}\right), 29.80\left(\left(\mathrm{CH}_{2}\right)_{2} \mathrm{CH}_{2}\left(\mathrm{CH}_{2}\right)_{4} \mathrm{CH}_{3}\right)$, $29.76\left(\left(\mathrm{CH}_{2}\right)_{3} \mathrm{CH}_{2}\left(\mathrm{CH}_{2}\right)_{3} \mathrm{CH}_{3}\right), 24.52\left(\left(\mathrm{CH}_{2}\right)_{4} \mathrm{CH}_{2}\left(\mathrm{CH}_{2}\right)_{2} \mathrm{CH}_{3}\right), 23.05\left(\left(\mathrm{CH}_{2}\right)_{5} \mathrm{CH}_{2} \mathrm{CH}_{2} \mathrm{CH}_{3}\right), 14.48$ $\left(\left(\mathrm{CH}_{2}\right)_{6} \mathrm{CH}_{2} \mathrm{CH}_{3}\right), 12.30\left(\left(\mathrm{CH}_{2}\right)_{7} \mathrm{CH}_{3}\right)$. FTIR $(\mathrm{KBr}): v=2953 \mathrm{~cm}^{-1}(\mathrm{C}-\mathrm{H}), 2921 \mathrm{~cm}^{-1}(\mathrm{C}-\mathrm{H}), 2850$ $\mathrm{cm}^{-1}(\mathrm{C}-\mathrm{H}), 1514 \mathrm{~cm}^{-1}(\mathrm{C}=\mathrm{C}), 1454 \mathrm{~cm}^{-1}(\mathrm{C}=\mathrm{C}), 1427 \mathrm{~cm}^{-1}(\mathrm{C}=\mathrm{N}), 1374 \mathrm{~cm}^{-1}(\mathrm{C}-\mathrm{H}), 1356 \mathrm{~cm}^{-1}(\mathrm{C}-\mathrm{H})$. Combustion elemental analysis calculated for $\mathrm{C}_{39} \mathrm{H}_{69} \mathrm{Au}_{3} \mathrm{~N}_{6}: \mathrm{C}, 38.62 ; \mathrm{H}, 5.73 ; \mathrm{N}, 6.93 ; \mathrm{Au}, 48.72$. Found: C, 38.45; H, 5.64; N, 6.90; Ash, 47.9.

\subsection{Single Crystal X-ray Structure}

The molecular structure and crystal packing structure were determined by single crystal X-ray structural analysis. Single crystals of gold(I) complexes were obtained by slow evaporation from a mixed solvent system (dichloromethane/acetone). Each crystal was mounted on a glass fiber, and the omega scanning technique was used to collect the reflection data using a D8 goniometer (Bruker, Billerica, MA, USA) with monochromatic Mo K $\alpha$ radiation $(\lambda=0.71075 \AA$ A ) for DT6 or a automated four-circular-axis diffractometer AFC-5R (Rigaku, Tokyo, Japan) with graphite monochromatized Cu $\mathrm{K} \alpha$ radiation $(\lambda=1.54178 \AA$ ) for DT7 and DT8. To investigate the actual crystal structures of the materials used, the measurements were performed at ambient temperature (296 K). For DT6, the initial structure of each unit cell was determined using a direct method in APEX3. The structural models were refined using a full-matrix least squares method in SHELXL-2014/6 [39,40]. All calculations were performed using SHELXL programs (University of Gottingen, Germany). For DT7 and DT8, the initial structure in the unit cell was determined by a direct method using SIR92 [41]. The structure model was refined by full-matrix least-squares methods using SHELXL97 (University of Gottingen, Germany) [40]. All calculations were performed in the crystallographic software package WinGX (1.80, Farrugia, UK) [42]. When the alkyl chains were disordered, the occupancy of the atoms was separated into two parts. The crystal data are summarized in Table S1, and are included in the Cambridge Crystallographic Data Centre (CCDC) database as reference numbers CCDC 1910566-1910568 for DT6, DT7, and DT8, respectively. The indexed database contains additional supplementary crystallographic data for this paper and may be accessed without charge at http://www.ccdc.cam.ac.uk/conts/retrieving.html.

\subsection{Photophysical Properties}

UV-visible absorption and steady-state photoluminescence spectra were recorded using a V-550 absorption spectrophotometer (JASCO, Tokyo, Japan) and a F-7500 fluorescence spectrophotometer (Hitachi, Tokyo, Japan), respectively. The quantum yields of the photoluminescence were determined using a Quantaurus-QY absolute photoluminescence quantum yield spectrometer (C11347-01, Hamamatsu Photonics, Hamamatsu, Japan). Photoluminescence decay profiles were measured using a $\mathrm{N}_{2}$ laser (USHO Pulsed dye laser, KEC-160; wavelength, 337 nm; pulse width, 600 ps; 10 Hz) with a streak camera (C4334, Hamamatsu Photonics, Hamamatsu, Japan). 


\subsection{Computational Studies}

The TD-DFT calculations were performed using the Gaussian 03 (revision E.01, Gaussian, Inc., Wallingford, CT, USA) program package, employing B3LYP hybrid functionals with SDD (for the $\mathrm{Au}$ atoms) and 6-311G+(d,p) (for the other atoms) basis sets [43]. The computation was carried out for the dimer formed in the crystal using the initial conformation obtained from the X-ray crystallography results. The vertical excitation energies and oscillator strengths were estimated for the 8 lowest transitions to excited singlets.

\section{Conclusions}

In conclusion, crystalline trinuclear Au complexes were prepared and displayed highly efficient $(\Phi=\sim 75 \%)$ RTP in the presence of air. The complexes indicated multiple dual-mode intermolecular interactions ( $\mathrm{Au}-\mathrm{Au}$ and $\mathrm{Au}-\pi$ interactions), which led to the formation of a supramolecular dimer and a polymer, and these interactions played a crucial role in the highly efficient, in-air RTP. This intense RTP appeared in the long wavelength region $(\sim 730 \mathrm{~nm})$, accompanied by an extremely large Stokes shift of $2.2 \times 10^{4} \mathrm{~cm}^{-1}(450 \mathrm{~nm})$. The efficient in-air RTP and the large Stokes shifts of the complexes developed are desirable properties which will be useful in development of photoluminescence materials. The Au complexes are expected to have potential applications in luminescent probes for bioimaging and for chemical sensing, and spectral conversion materials for displays, photovoltaic cells, plant cultivation, and related technologies [44-49].

Supplementary Materials: The following are available online at http://www.mdpi.com/1420-3049/24/24/4606/s1. Scheme S1: Synthesis route of DTn; Figures S1-S3: ${ }^{1} \mathrm{H}$ and ${ }^{13} \mathrm{C}-\mathrm{NMR}$ spectra; Figures S4 and S5: Crystal structures; Figure S6: Absorption spectra; Figure S7: Photoluminescence spectra in solution and in crystal; Figure S8: Photoluminescence spectra used for estimation of quantum yield; Figure S9: Decay profiles; Table S1: Crystallographic data; Table S2: Excitation energies and oscillator strengths.

Author Contributions: Conceptualization, O.T.; methodology, M.T., H.N., S.S., K.F., and K.H.; formal analysis K.F. and K.H.; investigation, M.T., H.N., S.S., Y.K., and K.Y.; writing-original draft preparation, O.T. and S.P.; writing-review and editing, S.P., K.F., and K.H.; visualization, K.F. and K.H.

Funding: This research received financial support by JSPS KAKENHI, 18K05265, 18H03764 (for OT), and 19K21131 (for KH); JST A-STEP, JPMJTM19C9; Japan-Egypt Research Cooperative Program (JSPS/MOSR-STDF); JICA Collaboration Kick-starter Program (RU/IITH); Ritsumeikan Global Innovation Research Organization (R-GIRO); Cooperative Research Program of the Network Joint Research Centre for Materials and Devices (Tokyo Institute of Technology).

Conflicts of Interest: The authors declare no conflict of interest.

\section{References}

1. Mei, J.; Leung, N.L.; Kwok, R.T.; Lam, J.W.; Tang, B.Z. Aggregation-Induced Emission: Together We Shine, Unite We Soar! Chem. Rev. 2015, 115, 11718-11940. [CrossRef] [PubMed]

2. Qin, A.; Tang, B.Z. Aggregation-Induced Emission: Fundamentals; John Wiley\& Sons, Ltd.: West Sussex, UK, 2014.

3. Hong, Y.; Lam, J.W.Y.; Tang, B.Z. Aggregation-Induced Emission. Chem. Soc. Rev. 2011, 40, 5361-5388. [CrossRef] [PubMed]

4. Birks, J.B. Photophysics of Aromatic Molecules; Wiley: London, UK, 1970.

5. Malkin, J. Photophysical and Photochemical Properties of Aromatic Compounds; CRC Press: Boca Raton, FL, USA, 1992.

6. Ronda, C.R. Luminescence: From Theory to Applications; Ronda, C.R., Ed.; Wiley-VCH Verlag GmbH \&Co. KGaA: Weinheim, Germany, 2008; pp. 1-34.

7. Leung, C.W.; Hong, Y.; Chen, S.; Zhao, E.; Lam, J.W.; Tang, B.Z. A photostable AIE luminogen for specific mitochondrial imaging and tracking. J. Am. Chem. Soc. 2013, 135, 62-65. [CrossRef] [PubMed]

8. Liang, G.D.; Lam, J.W.Y.; Qin, W.; Li, J.; Xie, N.; Tang, B.Z. Molecular luminogens based on restriction of intramolecular motions through host-guest inclusion for cell imaging. Chem. Commun. 2014, 50, 1725-1727. [CrossRef] [PubMed] 
9. Wang, X.; Hu, J.; Liu, T.; Zhang, G.; Liu, S. Highly sensitive and selective fluorometric off-on $\mathrm{K}^{+}$probe constructed via host-guest molecular recognition and aggregation-induced emission. J. Mater. Chem. 2012, 22, 8622-8628. [CrossRef]

10. Huang, J.; Tang, R.; Zhang, T.; Li, Q.; Yu, G.; Xie, S.; Liu, Y.; Ye, S.; Qin, J.; Li, Z. A New Approch to prepare Efficient Blue AIE Emitters for Undoped OLEDs. Chemistry 2014, 20, 5317-5326. [CrossRef]

11. Li, H.; Chi, Z.; Zhang, X.; Xu, B.; Liu, S.; Zhang, Y.; Xu, J. New Thermally Stable Aggregation-Induced Emission Enhancement Compounds for Non-Doped Red Light-Emitting Diodes. Chem. Commun. 2011, 47, 11273-11275. [CrossRef]

12. Zhoa, W.; Cheung, T.S.; Jiang, N.; Huang, W.; Lam, J.W.Y.; Zhang, X.; He, Z.; Tang, B.Z. Boosting the Efficiency of Organic Persistent Room-Temperature Phosphorescence by Intramolecular Triplet-Triplet Energy Transfer. Nat. Commun. 2019, 10, 1595. [CrossRef]

13. Crespo, O. Modern Supramolecular Gold Chemistry; Laguna, A., Ed.; Wiley-VCH Verlag GmbH \&Co. KGaA: Weinheim, Germany, 2009; pp. 65-129.

14. Yam, V.W.W.; Au, V.K.; Leung, S.Y. Light-Emission Self-Assembled Materials Based on $\mathrm{d}^{8}$ and $\mathrm{d}^{10} \mathrm{Transition}^{-}$ Metal Complexes. Chem. Rev. 2015, 115, 7589-7728. [CrossRef]

15. Yang, C.; Messerschmidt, M.; Coppens, P.; Omary, M.A. Trinuclear Gold(I) Triazolates: A New Class of Wide-Band Phosphors and Sensors. Inorg. Chem. 2006, 45, 6592-6594. [CrossRef]

16. Schmidbaur, H. The Aurophilicity Phenomenon: A Decade of Experimental Findings, Theoretical Concepts and Emerging Applications. Gold Bull. 2000, 33, 3-10. [CrossRef]

17. Schmidbaur, H.; Schier, A. Aurophilic Interactions as a Subject of Current Research: An Up-Date. Chem. Soc. Rev. 2012, 41, 370-412. [CrossRef] [PubMed]

18. Baron, M.; Tubaro, C.; Biffis, A.; Basato, M.; Graiff, C.; Poater, A.; Cavallo, L.; Armaroli, N.; Accorsi, G. Blue-Emitting Dinuclear $N$-heterocyclic Dicarbene Gold(I) Complex Featuring a Nearly Unit Quantum Yield. Inorg. Chem. 2012, 51, 1178-1784. [CrossRef] [PubMed]

19. Kishimura, A.; Yamasita, T.; Aida, T. Phosphorescent Organogels via "Mettalophilic" Interactions for Reversible RGB-Color Switching. J. Am. Chem. Soc. 2005, 127, 179-183. [CrossRef] [PubMed]

20. White-Morris, R.L.; Olmstead, M.M.; Attar, S.; Balch, A.L. Intermolecular Interactions in Polymorphs of Trinuclear Gold(I) Complexes: Insight into the Solvoluminescence of $\mathrm{Au}_{3}^{\mathrm{I}}(\mathrm{MeN}=\mathrm{COMe})_{3}$. Inorg. Chem. 2005, 44, 5021-5029. [CrossRef] [PubMed]

21. Balch, A.L.; Olmstead, M.M.; Vickery, J.C. Gold(I) Compounds without Significant Aurophilic Intermolecular Interactions: Synthesis, Structure, and Electronic Properties of $\mathrm{Ph}_{3} \mathrm{PAuC}(\mathrm{O}) \mathrm{NHMe}$ and $\mathrm{Au}_{3}\left(\mathrm{PhCH}_{2} \mathrm{~N}=\mathrm{COMe}\right)_{3}$ : Comparative Monomeric and Trimeric Analogues of the Solvoluminescent Trimer, $\mathrm{Au}_{3}(\mathrm{MeN}=\mathrm{COMe})_{3}$. Inorg. Chem. 1999, 38, 3494-3499.

22. Vickery, J.C.; Olmstead, M.M.; Fung, E.Y.; Balch, A.L. Solvent-Stimulated Luminescence from the Supramolecular Aggregation of a Trinuclear Gold (i) Complex that Displays Extensive Intermolecular AucA Au Interactions. Angew. Chem. Int. Ed. Engl. 1997, 36, 1179-1181. [CrossRef]

23. Ito, H.; Saito, T.; Oshima, N.; Kitamura, N.; Ishizaka, S.; Hinatsu, Y.; Wakeshima, M.; Tsuge, K.; Sawamura, M. Reversible Mechanochromic Luminescence of $\left[\left(\mathrm{C}_{6} \mathrm{~F}_{5} \mathrm{Au}\right]_{2}(\mu-1,4\right.$-diisocyanobenzene $\left.)\right]$. J. Am. Chem. Soc. 2008, 130, 10044-10045. [CrossRef]

24. Ito, H.; Muromoto, M.; Kurenuma, S.; Ishizaka, S.; Kitamura, N.; Sato, H.; Seki, T. Mechanical Stimulation and Solid Seeding Trigger Single-Crystal-to-Single-Crystal Molecular Domino Transformations. Nat. Commun. 2013, 4, 2009. [CrossRef]

25. Seki, T.; Sakurada, K.; Muromoto, M.; Ito, H. Photoinduced Single-Crystal-to-Single-Crystal Phase Transition and Photosalient Effect of a Gold(I) Isocyanide Complex with Shortening of Intermolecular Aurophilic Bonds. Chem. Sci. 2015, 6, 1491-1497. [CrossRef]

26. Seki, T.; Takamatsu, Y.; Ito, H. A Screening Approach for the Discover of Mechanochromic Gold(I) Isocyanide Complexes with Crystal-to-Crystal Phase Transitions. J. Am. Chem. Soc. 2016, 138, 6252-6260. [CrossRef] [PubMed]

27. Sathyanarayana, A.; Nakamura, S.; Hisano, K.; Tsutsumi, O.; Srinivas, K.; Prabusankar, G. Controlling the Solid-State Luminescence of Gold(I) N-Heterocyclic Carbene Complexes through Change in the Structure of Molecular Aggregates. Sci. China Chem. 2018, 61, 957-965. [CrossRef] 
28. Yamada, S.; Rokusha, Y.; Kawano, R.; Fujisawa, K.; Tsutsumi, O. Mesogenic Gold Complexes Showing Aggregation-Induced Enhancement of Phosphorescence in Both Crystalline and Liquid-Crystalline Phases. Faraday Discuss. 2017, 196, 269-283. [CrossRef] [PubMed]

29. Kawano, R.; Younis, O.; Ando, A.; Rokusha, Y.; Yamada, S.; Tsutsumi, O. Photoluminescence from Au(I) Complexes Exhibiting Color Sensitivity to the Structure of the Molecular Aggregates. Chem. Lett. 2016, 45, 66-68. [CrossRef]

30. Fujisawa, K.; Yamada, S.; Yanagi, Y.; Yoshioka, Y.; Kiyohara, A.; Tsutsumi, O. Tunning the Photoluminescence of Condensed-Phase Cyclic Trinuclear Au(I) Complexes through Control of Their Aggregated Structures by External Stimuli. Sci. Rep. 2015, 5, 7934. [CrossRef] [PubMed]

31. Fujisawa, K.; Okuda, Y.; Izumi, Y.; Nagamatsu, A.; Rokusha, Y.; Sadaike, Y.; Tsutsumi, O. Reversible Thermal-Mode Control of Luminescence fromLiquid-Crystalline Gold(I) Complexes. J. Mater. Chem. C 2014, 2, 3549-3555. [CrossRef]

32. Fujisawa, K.; Kawakami, N.; Onishi, Y.; Izumi, Y.; Tamai, S.; Sugimoto, N.; Tsutsumi, O. Photoluminescent Properties of Liquid Crystalline Gold(I) Isocyanide Complexes with a Rod-Like Molecular Structure. J. Mater. Chem. C 2013, 1, 5359-5366. [CrossRef]

33. Baeberá, J.; Elduque, A.; Giménez, R.; Ora, L.A.; Serrano, J.L. Pyrazolate “Golden" Rings: Trinuclear Complexes That Form Columnar Mesophases at Room Temperature. Angew. Chem. Int. Ed. Engl. 1996, 35, 2832-2835. [CrossRef]

34. Kim, S.J.; Kang, S.H.; Park, K.M.; Kim, H.; Zin, W.C.; Choi, M.G.; Kim, K. Trinuclear Gold(I) Pyrazolate Complexes. Exhibiting Heaxagonal Columnar Mesophases with Only Three Side-Chains. Chem. Mater. 1998, 10, 1889-1893. [CrossRef]

35. Cored, J.; Crespo, O.; Serrano, J.L.; Elduque, A.; Giménez, R. Decisive Influence of the Metal in Multifunctional Gold, Silver, and Copper Metallacycles: High Quantum Yield Phosphorescence, Color Switching, and Liquid Crystalline Behavior. Inorg. Chem. 2018, 57, 12632-12640. [CrossRef]

36. Tiekink, E.R.T.; Zukerman-Schpector, J. Gold $\cdots \pi$ Aryl Interactions as Supramolecular Synthons. CrystEngComm 2009, 11, 1176-1186. [CrossRef]

37. Yuan, W.Z.; Zhang, Y.; Tang, B.Z. Aggregation-Induced Emission: Applications; Tang, B.Z., Qin, A., Eds.; John Wiley \& Sons: London, UK, 2013; pp. 43-60.

38. Yaun, W.Z.; Shen, X.Y.; Zhao, H.; Lam, J.W.Y.; Tang, L.; Lu, P.; Wang, C.; Liu, Y.; Wang, Z.; Zheng, Q.; et al. Crystallization-Induced Phosphorescence of Pure Organic Luminescence at Room Temperature. J. Phys. Chem. C 2010, 114, 6090-6099. [CrossRef]

39. Sathish, V.; Ramdass, A.; Thanasekaran, P.; Lu, K.L.; Rajagopal, S. Aggregation-Induced Phosphorescence Enhancement (AIPE) Base on Transition Metal Complexes-An overview. J. Photochem. Photobiol. C Photochem. Rev. 2015, 23, 25-44. [CrossRef]

40. Sheldrick, G.M. SHELXS-2014, Program for Crystal Structure Solution; University of Göttingen: Göttingen, Germany, 2014.

41. Sheldrick, G.M. A Short History of SHELX. Acta Crystallogr. Sect. A Found Crystallogr. 2008, 64, 112-122. [CrossRef]

42. Altomare, A.; Cascarano, G.; Giacovazzo, C.; Guagliardi, A. Completion and Refinement of Crystal Structure with SIR92. J. Appl. Crystallogr. 1993, 26, 343-350. [CrossRef]

43. Farrugia, L.J. WinGx Suite for Small-Molecule Single-Crystal Crystallography. J. Appl. Crystallogr. 1999, 32, 837-838. [CrossRef]

44. Frisch, M.J.; Trucks, G.W.; Scuseria, G.E.; Robb, M.A.; Cheeseman, J.R.; Montgomery, J.A.; Vreven, J.T.; Kudin, K.N.; Burant, J.C.; Millam, J.M.; et al. Gaussian 03, Revision, E.01; Gaussian, Inc.: Wallingford, CT, USA, 2004.

45. Qin, W.; Alifu, N.; Cai, Y.; Lam, J.W.Y.; He, X.; Su, H.; Zhang, P.; Qian, J.; Tang, B.Z. Synthesis of an Efficient Far-Red/Near-Infrared Luminogen with AIE Characteristic for in vivo Bioimaging Applications. Chem. Commun. 2019, 55, 5615-5618. [CrossRef]

46. Kanosue, K.; Ando, S. Polymides with Heavy Halogens Exhibiting Room-Temperature Phosphorescence with Very Large Stokes Shifts. ACS Macro Lett. 2016, 5, 1301-1305. [CrossRef]

47. He, T.; Wang, Y.; Tian, X.; Gao, Y.; Zhao, X.; Grimsdale, A.C.; Lin, X.; Sun, H. An Organic Dye with Very Large Stockes-Shift and Broad Tunability of Fluorescence: Potentail Two-Photon Probe for Bioimaging and Ultra-Sensitive Solid-State Gas Sensor. Appl. Phys. Lett. 2016, 108, 011901. [CrossRef] 
48. Turrisi, R.; Sanguineti, A.; Sassi, M.; Savoie, B.; Takai, A.; Patriarca, G.E.; Salamone, M.M.; Ruffo, R.; Vaccaro, G.; Meinardi, F.; et al. Stokes Shift/Emission Efficiency Trade-Off in Donor-Acceptor Perylenemonoimides for Luminescenct Solar Concentrators. J. Mater. Chem. A 2015, 3, 8045-8054. [CrossRef]

49. Zhu, Y.; Qiu, Z.; Ai, B.; Lin, Y.; Zhou, W.; Zhang, J.; Yu, L.; Mi, Q.; Lian, S. Significant Improved Quantum Yield of $\mathrm{CaAl}_{12} \mathrm{O}_{19}$ : $\mathrm{Mn}^{4+}$ Red Phosphor by Co-Doping $\mathrm{Bi}^{3+}$ and $\mathrm{B}^{3+}$ Ions and Dual Application for Plant Cultivations. J. Lumin. 2018, 201, 314-320. [CrossRef]

Sample Availability: Not available.

(C) 2019 by the authors. Licensee MDPI, Basel, Switzerland. This article is an open access article distributed under the terms and conditions of the Creative Commons Attribution (CC BY) license (http://creativecommons.org/licenses/by/4.0/). 